University of Wollongong

Research Online

Faculty of Engineering - Papers (Archive)

Faculty of Engineering and Information

Sciences

$1-1-2010$

\title{
Modeling of strip shape during cold rolling of thin strip
}

Zhengyi Jiang

University of Wollongong, jiang@uow.edu.au

Xiaozhong Du

University of Wollongong, xdu@uow.edu.au

Yi Du

University of Wollongong, ydu@uow.edu.au

Dongbin Wei

University of Wollongong, dwei@uow.edu.au

M Hay

University of Wollongong

Follow this and additional works at: https://ro.uow.edu.au/engpapers

Part of the Engineering Commons

https://ro.uow.edu.au/engpapers/3485

\section{Recommended Citation}

Jiang, Zhengyi; Du, Xiaozhong; Du, Yi; Wei, Dongbin; and Hay, M: Modeling of strip shape during cold rolling of thin strip 2010, 9-14.

https://ro.uow.edu.au/engpapers/3485

Research Online is the open access institutional repository for the University of Wollongong. For further information contact the UOW Library: research-pubs@uow.edu.au 


\title{
Modelling of strip shape and profile during cold rolling of ultra thin strip
}

\author{
Zhengyi Jiang ${ }^{1, a}$, Xiaowei Cheng ${ }^{2, b}$, Xiaozhong $\mathrm{Du}^{3, \mathrm{~b}}$, Dongbin Wei $\mathrm{i}^{4, \mathrm{~d}}$ and \\ Xiaofeng $\mathrm{He}^{5, \mathrm{e}}$ \\ 1, 2, 3, 4School of Mechanical, Materials and Mechatronic Engineering, University of Wollongong, \\ Wollongong NSW 2522, Australia

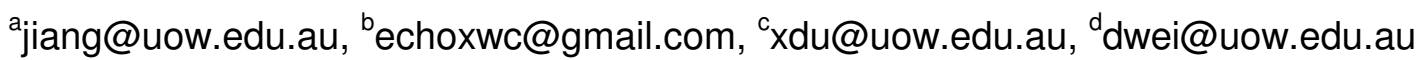 \\ 'hexiaofeng3@163.com
}

Keywords: Strip shape, ultra thin strip, cold rolling, modelling.

\begin{abstract}
In this paper, finite element models of the strip shape during cold rolling of ultra thin strip in both symmetrical and asymmetrical rolling cases have been successfully developed, and the strip shape such as the thickness distribution along the strip width has been obtained. The strip shape and edge drop are discussed under both symmetrical and asymmetrical rolling conditions. Simulation results show that the asymmetrical rolling can reduce strip edge drop dramatically. The work roll edge curve also affects strip shape significantly. The developed finite element model has been verified with the experimental values.
\end{abstract}

\section{Introduction}

Cold rolling is an essential method to manufacture the sheet and foil products of metals. For thinner strip such as the foil or the thin strip involves the control of the strip dimensional accuracy, the strip crown and surface finish. The influenced factors are relevant to the deformation feature in the roll bite and to surface roughness during rolling practice. Therefore, it is essential for researchers and manufacturers to understand the strip shape performance in cold rolling of thin strip. The advanced science and technology requires thin gauge strip increasingly, and the quality issues such as the strip shape and surface quality become more and more concerns in the manufacturing of ultra thin gauge strip. Previous researchers have investigated strip shape, profile and flatness in rolling [1-4], and the control of the strip shape, profile and flatness [5] no longer present a serious challenge to rolling mill operation for relatively thick products. However, for ultra thin strip such as foil is still a challenge in rolling practice, this involves the control of the strip dimensional accuracy, strip shape and surface finish. In this work, the finite element (FE) modelling of the strip shape and profile during cold rolling of ultra thin strip has been carried out, and the FE simulation results are compared for both symmetrical and asymmetrical rolling, and verified with the measured values.

\section{Theoretical Formulation}

The finite element models generated are usually nonlinear and can involve from a few to many thousand variables. In terms of these variables, the equilibrium equations can be obtained by minimising the following functional [6]:

$$
\phi=\int_{V} \sigma_{i j} \delta \dot{\varepsilon}_{i j} d V-\int_{S_{p}} \bar{p}_{i} \delta v_{i} d s
$$

where $\sigma_{i j}$ is the stress, $v_{\mathrm{i}}$ is the velocity and $\boldsymbol{\varepsilon}_{i j}$ is the strain. The true velocity field $\boldsymbol{v}_{\mathrm{i}}$ satisfies the minimum of the functional, that is

$$
\frac{\delta \phi}{\delta v_{i}}=0
$$


The equilibrium equations can be written symbolically as

$$
F^{N}\left(u^{M}\right)=0
$$

where $\boldsymbol{F}^{N}$ is the force component conjugate to the $N$ th variable in the problem, and $u^{M}$ is the value of the $M$ th variable. The basic problem is to solve Eq. (3) for $u^{M}$ throughout the history of interest. The Newton's method is used to solve the nonlinear equilibrium equations [6]. The relationship between the strain rate and velocity is

$$
\dot{\varepsilon}_{i j}=\frac{1}{2}\left(v_{i, j}+v_{j, i}\right)
$$

where $v_{\mathrm{i}}$ is the velocity and $\dot{\varepsilon}_{i j}$ is the strain rate. The external force boundary condition applied on interface $S_{p}$ is as follows:

$$
\sigma_{i j} n_{j}=\bar{p}_{i}
$$

where $n_{j}$ is the unit outward normal to $S_{p}$ at the point, and $\bar{p}_{i}$ is the external force.

In the simulation, the constant friction was employed as follows:

$$
\tau=\mu N
$$

where $\mu$ is the coefficient of friction and $N$ is the normal force.

\section{Simulation Conditions}

Fig. 1a shows a 4-high cold strip rolling. Due to symmetry, one half of the roll and strip system is selected. $h_{0}$ and $h_{1}$ are the strip thickness before and after rolling respectively, $v_{0}$ and $v_{1}$ the strip speeds before and after rolling respectively, $V$ the work roll speed, $R_{\mathrm{w}}$ the radius of the work roll, $l$ the length of the roll bite, $R_{\mathrm{b}}$ the radius of the backup roll, $\alpha$ the roll bite angle, $\mathrm{O}_{\mathrm{b}}$ the central point of the backup roll, and $\mathrm{O}_{\mathrm{w}}$ the central point of the work roll. If the asymmetrical rolling is employed to roll ultra thin strip, as shown in Fig. 1b [7], the upper and down work rolls have different speeds, in which a shear cross region is generated [8]. $R_{1}$ and $R_{2}$ are the upper and down radii of work rolls respectively, $V_{1}$ and $V_{2}$ the speeds of the upper and down work rolls respectively, $x_{\mathrm{n} 1}$ and $x_{\mathrm{n} 2}$ the neutral points of the upper and down work rolls respectively, and $\mathrm{O}_{1}$ and $\mathrm{O}_{2}$ the central points of the upper and down work rolls respectively.

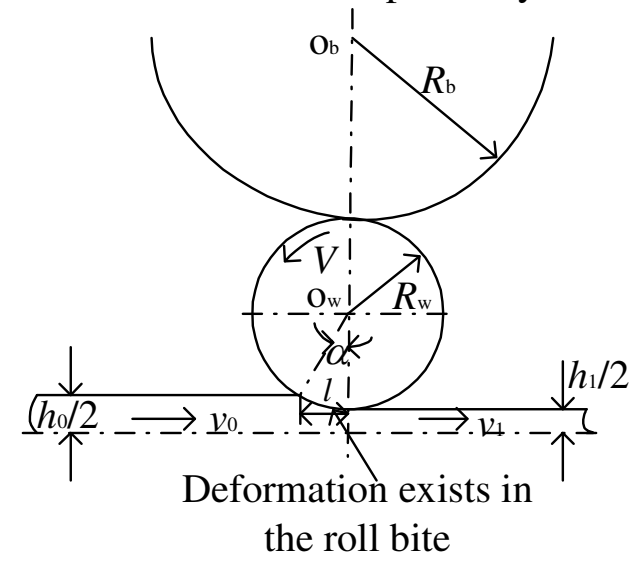

(a)

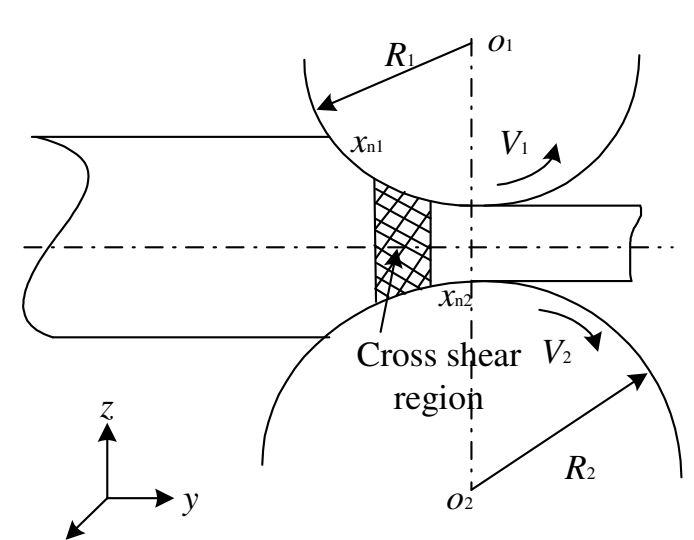

(b)

Fig. 1 Symmetrical rolling (a) and asymmetrical rolling (b) 
As a thinner strip is rolled, the strip shape problem will be a big concern during the rolling [5], and good strip shape is based on the mathematical models applied to the cold strip rolling. Elastic deformation of the rolls will result in problem in strip profile, shape, and flatness $[9,10]$.

Calculation parameters. The parameters used for 4-high asymmetrical rolling are the diameter of upper work roll $64 \mathrm{~mm}$, diameter of bottom work roll $80 \mathrm{~mm}$, speed ratio 1.33 (asymmetrical rolling), length of upper work roll $120 \mathrm{~mm}$ and length of bottom work roll $120 \mathrm{~mm}$. The FE model used for 4-high symmetrical rolling is shown in Fig. 2.

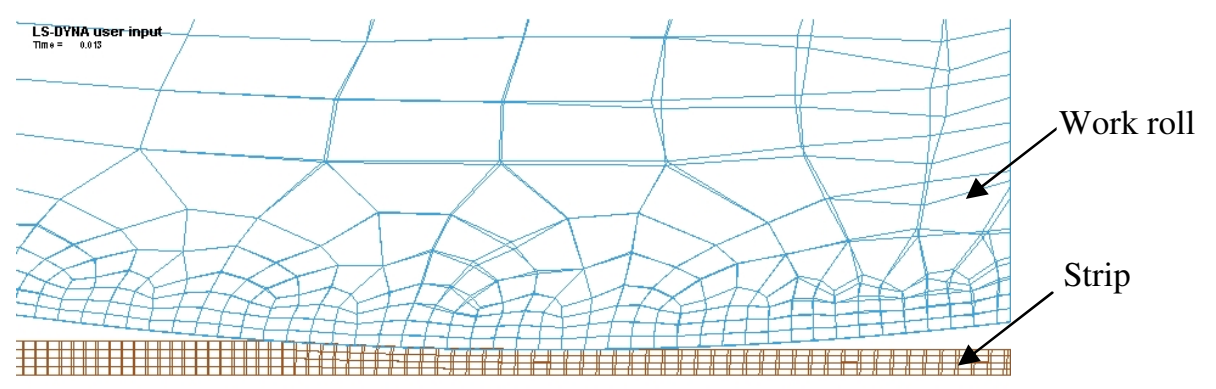

Fig. 2 FE model for symmetrical rolling

\section{Results and Discussion}

Strip crown. Fig. 3 shows the calculated crown of the cold rolled strip and its edge drop during symmetrical rolling. It can be seen that the strip edge drop is up to $2.7 \mu \mathrm{m}$. If the rolling force varies, the rolled strip profile and crown change, as shown in Fig. 4. It is clearly that the strip shape becomes poor, and the strip crown increases when the rolling force increases. This is due to the effect of rolling force on strip edge drop. If the rolling force increases, the strip edge drop becomes large, so the strip thickness at edges becomes small, and the strip crown increases.

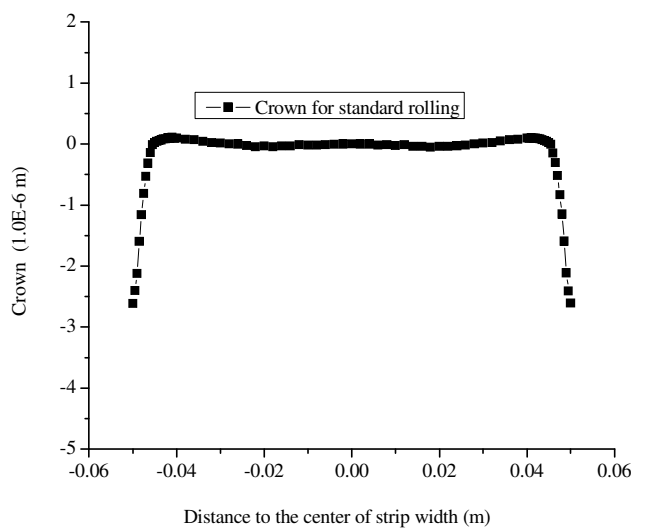

Fig. 3 Crown of the rolled strip in symmetrical rolling

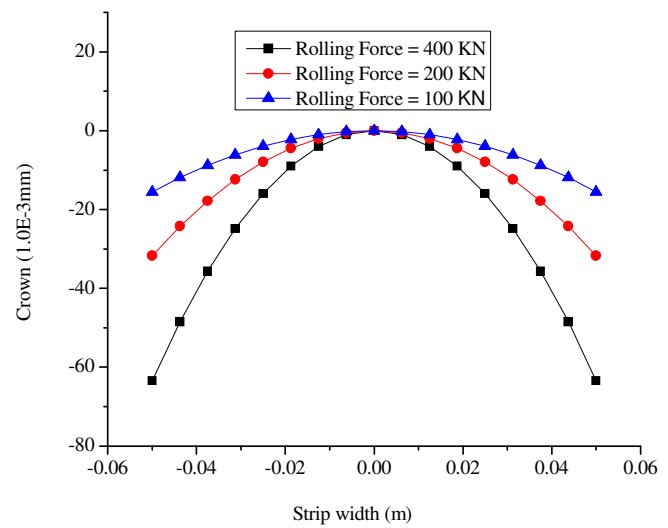

Fig. 4 Effect of rolling force on strip crown

The relationship between the final strip thickness and the crown of rolled strip is shown in Fig. 5 . It can be seen that there is a strip edge drop, but the effect of final strip thickness on strip edge drop is insignificant. Fig. 6 shows the strip shape during symmetrical and asymmetrical rolling. It can be seen that if the asymmetrical rolling is carried out, the strip edge drop decreases from 2.6 to $1.7 \mu \mathrm{m}$, a significant decrease during asymmetrical rolling of ultra thin strip. This is due to the existing of the cross shear region in the roll bite [8], which makes the rolling force decrease significantly, so the strip crown becomes small. This is very useful in cold rolling of ultra thin strip to improve the strip shape and reduce the energy cost significantly. 
Effect of roll edge shape. If the work roll is modified with a profile as shown in Fig. 7a, the calculated strip crown is obtained, as shown in Fig. 7b. It can be seen that the work roll profile has a significant influence on the strip crown, and the strip crown changes obviously at the edge when the work roll curve is applied. This indicates that a suitable work roll profile used in cold rolling of ultra thin strip can improve strip shape effectively.

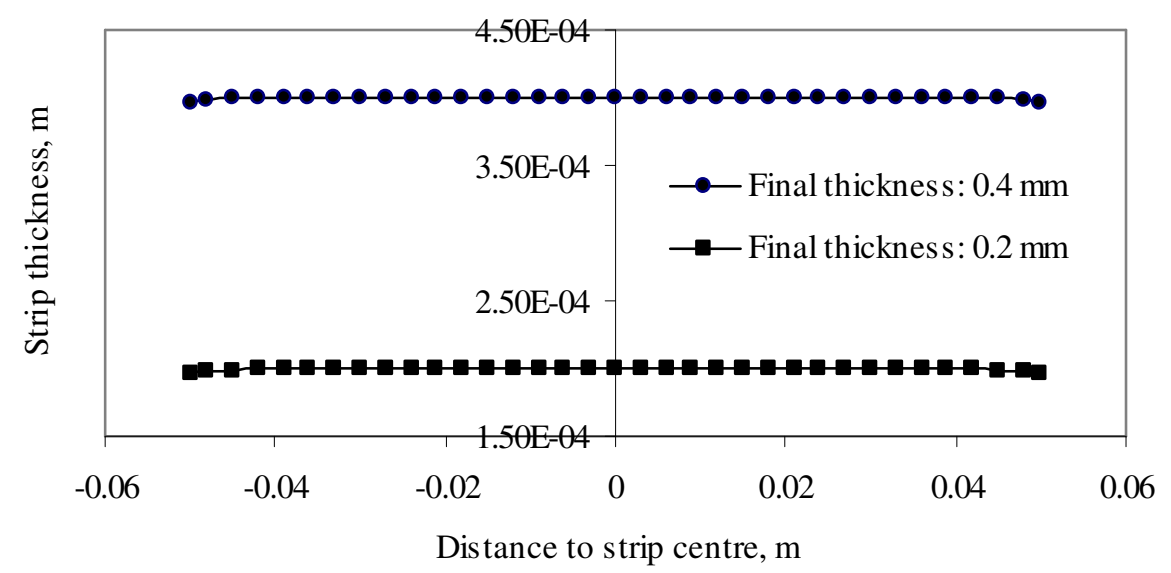

Fig. 5 Thickness distribution of the rolled strip with various final strip thickness

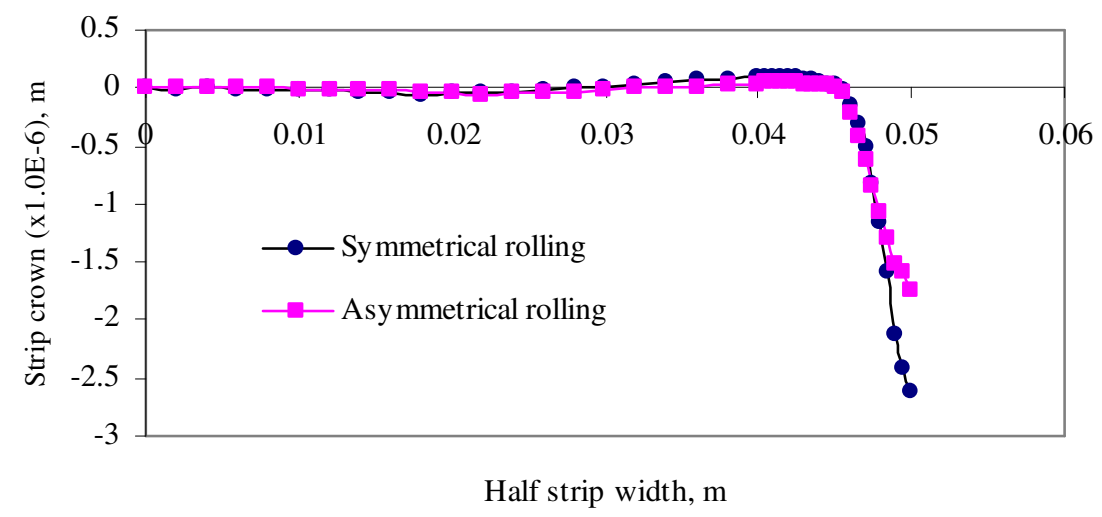

Fig. 6 Crowns of the rolled strip under asymmetrical and symmetrical rolling

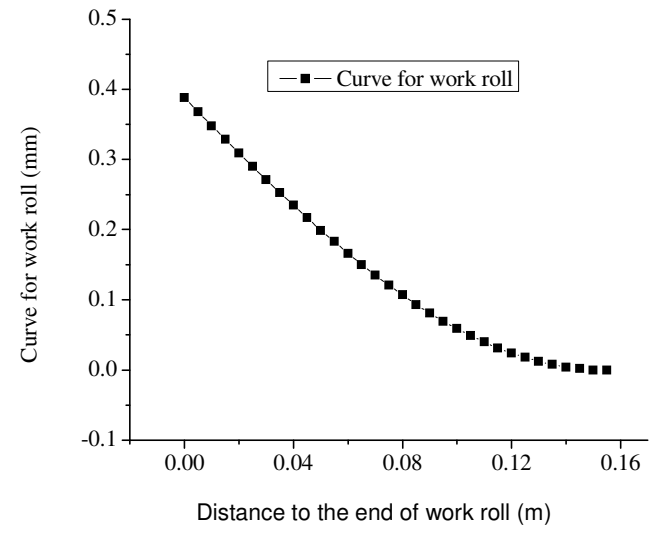

(a)

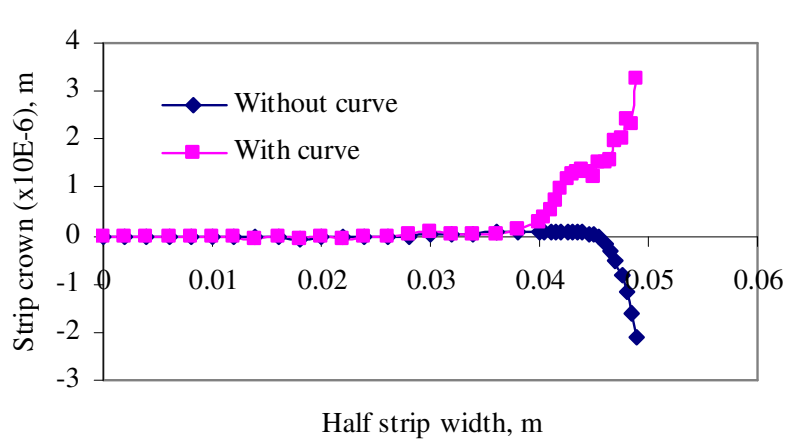

(b)

Fig. 7 Work roll curve (a) and strip crown (b)

In order to verify the finite element modelling of strip shape, the cold rolling of thin strip was conducted on Hille 100 rolling mill in laboratory [11]. In the experiment, when the rolling speed is 
$0.15 \mathrm{~m} / \mathrm{s}$, entry thickness of strip $0.55 \mathrm{~mm}$, exit thickness varies, strip width $100 \mathrm{~mm}$, and a low carbon steel was rolled, friction coefficient 0.1. A comparison of the calculated strip profile with measured value under asymmetrical rolling is shown in Fig. 8. It can be seen that the calculated thickness along the strip width is close to the measured values. This confirms the developed simulation model is applicable.

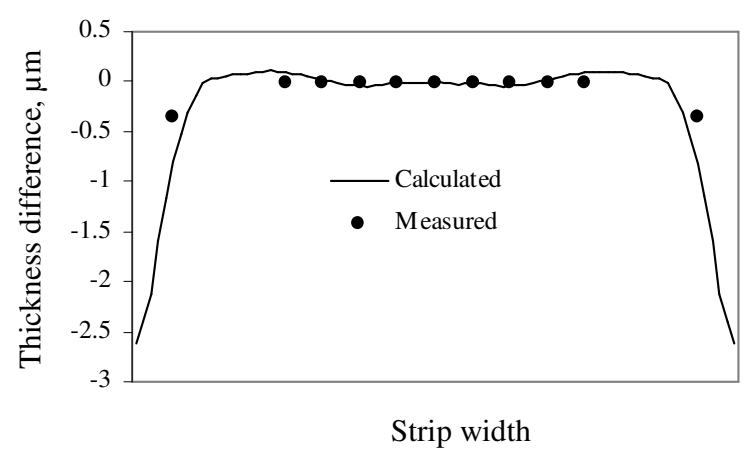

Fig. 8 Comparison of calculated strip thickness difference with measured values

\section{Summary}

Finite element modelling of the strip shape during cold rolling of ultra thin strip in both symmetrical and asymmetrical rolling cases has been successfully carried out, and the strip thickness distribution along the strip width has been obtained. Simulation results show that the asymmetrical rolling can reduce the strip edge drop dramatically, which is useful in improving the strip shape and reducing the energy cost in cold rolling of thin strip. The work roll edge curve can also change the strip shape significantly. The obtained results are applicable to control the rolled strip shape in clod rolling practice.

\section{Acknowledgements}

The authors gratefully acknowledge ARC funding support for the Discovery Project, including the Australian Research Fellowship for the first author. The authors also would like to thank Mr. Joe Abbott's assistance in the experimental work.

\section{References}

[1] H.-M. Liu, J.-C. Lian and Y. Peng: J. Mater. Proc. Technol. Vol. 116(2-3) (2001), p. 235.

[2] A.S. Deshpande and K.S. Murthy: J. Mater. Proc. Technol. Vol. 63(1-3) (1997), p. 712.

[3] Z.Y. Jiang and A.K. Tieu: JSME Int. J. Vol. 46(A3) (2003), p. 218.

[4] X.M. Zhang, Z.Y. Jiang, A.K. Tieu, X.H. Liu and G.D. Wang: J. Mater. Proc. Technol. Vol. 130-131 (2002), p. 219.

[5] G.D. Wang: The Shape Control and Theory (Metallurgical Industry Press, Beijing, 1986).

[6] Z.Y. Jiang and A.K. Tieu: J. Mater. Proc. Technol. Vol. 130-131 (2002), p. 511.

[7] Y.M Huang and G.Y. Tzou: Int. J. Mech. Sci. Vol. 39 (1997), p. 289.

[8] Z.Y. Jiang, H.T. Zhu and A.K. Tieu: Mater. Proc. Technol. Vol. 162-163 (2005), p. 512.

[9] Z.Y. Jiang and A.K. Tieu: Tribology Int. Vol. 37 (2004), p. 185. 
[10] Z.Y. Jiang, A.K. Tieu, X.M. Zhang, C. Lu and W.H. Sun: J. Mater. Proc. Technol. Vol. 140(1-3) (2003), p. 544.

[11] H. Xie: PhD Dissertation, University of Wollongong, 2011. 